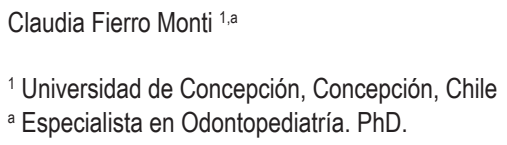

\section{Correspondencia:}

Claudia Fierro Monti: cfierro@udec.cl

Av Roosevelt 1550, Concepción, Chile. ORCID: 0000-0002-0308-6044

\section{Conflicto de intereses: ninguno.}

Fuente de financiamiento: autofinanciado.

Recibido: 01/08/21

Aceptado: $17 / 08 / 21$

Publicado: 05/10/21

\title{
Sr Editor.
}

El maltrato infantil es un problema mundial con graves consecuencias que pueden durar toda la vida. La OMS lo define como: "los abusos y la desatención de que son objeto los menores de 18 años, e incluye todos los tipos de maltrato físico o psicológico, abuso sexual, desatención, negligencia y explotación comercial o de otro tipo que causen o puedan causar un daño a la salud, desarrollo o dignidad del niño, o poner en peligro su supervivencia, en el contexto de una relación de responsabilidad, confianza o poder" ${ }^{1}$.

La evolución del concepto de abuso infantil lleva a considerar nuevos tipos de maltrato, incluyendo todas las experiencias adversas de la infancia (ACES, por sus siglas en inglés), definidas típicamente como eventos estresantes o traumáticos de la vida que ocurren durante los primeros años de vida, como tener un familiar drogadicto o alcohólico, con una enfermedad mental, depresión o con pensamientos suicidas en el hogar; encarcelamiento de cualquier miembro de la familia por un delito, muerte de un padre o abandono por divorcio de los padres, o ser testigo de violencia doméstica contra la madre ${ }^{2,3}$.

El estudio de las ACE (año1995-7) reveló que el estrés es un mecanismo biológico. Las experiencias traumáticas no simplemente les suceden a los niños, sino que ocurren dentro de sus cerebros y de sus cuerpos. El estrés hace que el cuerpo libere cortisol. La exposición prolongada a niveles altamente peligrosos de cortisol, conocido como estrés tóxico, afecta la capacidad y la habilidad de aprendizaje del cerebro ${ }^{3}$.

Sin embargo, el fenómeno de los menores migrantes no acompañados también se ha expandido, los niños en orfanato están sujetos fisiológica y emocionalmente a remodelaciones constantes en su entorno: los niños pequeños, en el bienestar infantil, a menudo tienen una respuesta al estrés que está desregulada. Se debe prestar más atención a los niños 
cuya madre fue asesinada. El homicidio de pareja íntima a menudo involucra el asesinato de familiares o transeúntes, como los hijos de la pareja, familiares o nuevos socios de las víctimas y tiene consecuencias a largo plazo en los miembros de la familia restantes ${ }^{4}$. La Asociación Pediátrica Dental Americana informa que el 30\% de los niños de sexto a décimo grado informan haber sido acosados y/o haber acosado a otros. Los niños con anomalías orofaciales o dentales (incluida la maloclusión) son frecuentemente sometidos a acoso y, como resultado, pueden sufrir graves consecuencias psicológicas, incluida la depresión y la ideación suicida, lo que conlleva a los proveedores de atención médica (incluidos los proveedores dentales) a preguntar a los pacientes sobre el acoso escolar y abogar por programas de prevención en las escuelas y otros entornos comunitarios ${ }^{5}$. Los profesionales de la salud que atienden nińos, como especialistas, entienden los efectos del trauma y el estrés tóxico, así como la importancia de construir relaciones positivas y de confianza.

Dentro de este contexto, un impacto real adicional en la odontopediatría y pediatría social está representado por los nuevos tipos de familias: estos cambios pueden atribuirse a varios factores, como las altas tasas de divorcio y las estructuras familiares heterogéneas, que se extienden más allá de los límites de las relaciones biológicas o conyugales. El desarrollo psicosocial de los nińos está vinculado tanto a sus relaciones con los padres como al contexto sociocultural en el que viven ${ }^{4,6}$.

Los pediatras y odontopediatras deben recibir capacitación para desempeñar un papel importante en el cuidado y apoyo del bienestar social y de desarrollo de los niños criados en familias con diversas configuraciones ${ }^{4}$. La prevención del maltrato infantil requiere un enfoque multisectorial, donde los diferentes especialistas contribuyan al reconocimiento precoz de los casos ayudando a reducir la recurrencia del maltrato y a paliar sus consecuencias 5 .
En conclusión, a medida que la sociedad y la cultura han cambiado progresivamente, han surgido diferentes configuraciones de abuso infantil y negligencia. La atención pediátrica se ha basado en una mayor conciencia de la importancia de satisfacer las necesidades psicosociales y de desarrollo de los niños y del papel de las familias en la promoción de la salud.

\section{Referencias bibliográficas}

1. Ajilian Abbasi M, Saeidi M, Khademi G, Hoseini B, Emami Moghadam Z. Child Maltreatment in the World: A Review Article. Intl J Ped. 2015;3(1.1):353-365. DOI: 10.22038/ijp.2015.3753

2. Hunt TKA, Slack KS, Berger LM. Adverse childhood experiences and behavioral problems in middle childhood. Child Abuse Negl. 2017;67:391-402. DOI: 10.1016/j. chiabu.2016.11.005.

3. Petruccelli K, Davis J, Berman T. Adverse childhood experiences and associated health outcomes: A systematic review and meta-analysis. Child Abuse Negl. 2019;97:104127. DOI: 10.1016/j.chiabu.2019.104127

4. Ferrara P, Bernasconi S. From "classic" child abuse and neglect to the new era of maltreatment. Ital J Pediatr. 2017;28;43(1):16. DOI: 10.1186/s13052-017-0336-1.

5. Fisher-Owens SA, Lukefahr JL, Tate AR, American Academy of Pediatric Dentistry, Council on Clinical Affairs, Council on Scientific Affairs, Ad Hoc Work Group on Child Abuse and Neglect, American Academy of Pediatrics, Section on Oral Health Committee on Child Abuse and Neglect. Oral and Dental Aspects of Child Abuse and Neglect. Pediatr Dent 2017;39(4):278-83. DOI: $10.1542 /$ peds.2017-1487

6. Schickedanz A, Halfon N, Sastry N, Chung PJ. Parents' Adverse Childhood Experiences and Their Children's Behavioral Health Problems. Pediatrics. 2018;142(2):e20180023. DOI: 10.1542/peds.20180023. 